\title{
Review of the British Thoracic Society Winter Meeting 2014, 3-5 December, London, UK
}

\author{
Neil J Greening, ${ }^{1,2}$ Ricardo J José, ${ }^{3}$ James D Chalmers, ${ }^{4}$ Samuel M Janes, ${ }^{5}$ on behalf \\ of the BTS Science and Research Committee
}

${ }^{1}$ Leicester Respiratory Biomedical Research Unit, Institute of Lung Health, Glenfield Hospital, Leicester, UK

${ }^{2}$ Department of Infection, Immunity and Inflammation, University of Leicester,

Leicester, UK

${ }^{3}$ Centre for Inflammation and Tissue Repair, University College London, London, UK ${ }^{4}$ Tayside Respiratory Research Group, University of Dundee, Dundee, UK

${ }^{5}$ Lungs for Living Research Centre, University College London, London, UK

\section{Correspondence to} Dr Sam M Janes, Lungs for Living Research Centre, University College London, 5 University Street, London WC1E 6JF, UK; s.janes@ucl.ac.uk

NJG, RJJ and JDC contributed equally.

Accepted 8 January 2015

\section{CrossMark}

To cite: Greening NJ, José RJ, Chalmers JD, et al. Thorax 2015;70:278-283.

\begin{abstract}
The British Thoracic Society Winter Meeting 2014 is reviewed in this article. This annual scientific meeting attracted its largest number of delegates ever and over 3 days in December up-to-date respiratory research was presented and current thinking in respiratory science and clinical academia was discussed. This article reviews a number of symposia and selected abstract presentations from the meeting.
\end{abstract}

\section{INTRODUCTION}

'When shall we three meet again? In thunder, lightning, or in rain?' And so plans to attend the British Thoracic Society (BTS) Winter Meeting 2014 were made. A record number of delegates attended this year's meeting, which included 24 major symposia (with 18 international speakers), 3 guest lectures and 26 spoken sessions, and a total of 144 spoken and 304 poster abstracts. Here, a selection of the authors' highlights are presented.

\section{PLENARY SCIENTIFIC SYMPOSIUM}

This year we heard from four of the UK's leading clinical academics who showcased their foremost research in respiratory medicine. Professor Stephen Gordon (Liverpool) spoke about his research into mucosal defence against Streptococcus pneumoniae, the most common cause of community-acquired pneumonia. Mucosal immunity is an important host-derived mechanism for naturally acquired protective immunity against lung infection with this pathogen. ${ }^{1}$ Additionally, he discussed the experimental human pneumococcal carriage model used by his group to investigate clearance of $S$. pneumoniae and protection against infection. ${ }^{2}$

Dr Alison Condliffe (Cambridge) described her research that led to the discovery of a novel genetic mutation in which there is a glutamic acid to lysine substitution at residue 1021 (E1021K), causing a primary immunodeficiency known as activated PI3K- $\delta$ syndrome. ${ }^{3}$ This specific immunodeficiency has been reported in a number of families and causes recurrent respiratory infections.

Professor Luca Richeldi (Southampton) discussed his research trying to identify patients with interstitial lung disease earlier with the aim of improving patient outcomes by commencing anti-fibrotic treatment before patients' lung function declines. ${ }^{4} \mathrm{His}$ research has identified good agreement between electronic interpretation of acoustic patterns of fibrotic lung sounds and assessment by expert physicians. Furthermore, he is investigating the correlation of these sounds obtained from recordings with electronic stethoscopes with high-resolution computed tomography images.

\section{GUEST LECTURES}

The guest lectures were a particular highlight this year, and covered multiple aspects of respiratory medicine.

Professor Sally Wenzel from the Asthma Institute, University of Pittsburgh, delivered The BTS Lecture on asthma phenotypes and described the evolution from clinical to molecular approaches. ${ }^{5}$ She reviewed the clinical and physiological features that historically been used to type asthma and then introduced more objective ways of phenotyping patients using cluster analysis. ${ }^{6}{ }^{7}$ These methods demonstrate how the different pathobiology and biomarkers are related to the clinical characteristics and can be used to establish separate subgroups of patients with asthma. Importantly, treatments that target specific pathways are now available for particular phenotypes. Finally, Professor Wenzel described the less wellunderstood non- $\mathrm{T}_{\mathrm{H}} 2$ asthma, in particular neutrophilic asthma, which is less responsive to corticosteroids.

The Morriston Davies Lecture was given by Professor Sir David Spiegelhalter (Cambridge) on communicating risk and uncertainty to the public and policy makers. This highly entertaining lecture was directly relevant to all those involved in talking to patients, as managing uncertainty is one of the most difficult skills. Using real life examples-such as the nationally reported risks of eating a rasher of bacon a day-he presented different ways of communicating risk and suggested that it is likely that expected frequencies and tree diagrams will become part of the standard reporting of trials, rather than absolute or relative risk. Indeed these approaches are already being used on patient information leaflets around disease screening.

This year's Snell Memorial Lecture was given by Professor Douglas Young (London), taking us back in time through phylogenetic trees to determine the origins of Mycobacterium tuberculosis. Although it is advocated that human tuberculosis was distributed throughout the world following the dispersal of humans from Africa, it is now suggested that sea mammals played a key role in transmitting the disease across oceans and to the different continents. $^{8}$

The president's address was given by the current American Thoracic Society (ATS) president, Professor Thomas Ferkol (Washington, USA), who detailed his journey as a clinical academic leading discovery science in cystic fibrosis, as well as 
highlighting recent emerging therapies that will change the outlook for these patients. Professor Ann Millar will continue as BTS president for another term as the elected president for this year, Professor Wisia Wedzicha (London), has taken up her role as the first non-American and first female editor-in-chief of the American Journal of Respiratory and Critical Care Medicine. During this session we were informed that BTS members will be able to attend the ATS 2015 meeting at ATS member rates.

\section{BTS/BRITISH ASSOCIATION FOR LUNG RESEARCH}

The BTS and British Association for Lung Research (BALR) have a long tradition of conducting joint sessions and this year we heard talks from exceptional speakers in two sessions on the topic of 'Modelling respiratory disease: current concepts for drug discovery'. In the first session, Professor Clive Page (London) described the usefulness of in vivo models to identify new drugs for respiratory disease, while $\mathrm{Dr}$ Chris Scotton (Exeter) spoke about novel ways of using in vivo imaging in murine models of lung disease, ${ }^{9}$ and Professor Stephen Renshaw (Sheffield) described how the zebrafish, which does not have lungs, is a useful model for studying pulmonary inflammation. ${ }^{10}$ In the second session, Professor Eric White (Michigan, USA) discussed novel 3D cell culture models for studying fibrotic lung disease, Professor Donna Davies (Southampton) described how novel tissue-engineered constructs with microfluidics platforms to deliver inflammatory cells will be used to develop novel therapeutic treatments for asthma, and Dr Carmel Nanthakumar (London) discussed how novel in vitro platforms are being used in industry to develop new antifibrotic drugs.

\section{BTS/BRITISH PAEDIATRIC RESPIRATORY SOCIETY}

This year's BTS/British Paediatric Respiratory Society (BPRS) symposium covered the emerging body of evidence on the role of the microbiome in respiratory disease. Professor Hans Bisgaard (Copenhagen) gave a very impressive talk on the role of the microbiome in viral-induced wheeze in children and, interestingly, found that most cases were actually associated with bacteria and not viruses, ${ }^{11}$ suggesting that childhood wheeze should be treated with antibiotics. A probable difference was also demonstrated between infants born by normal vaginal delivery and caesarean section, whereby infants born following caesarean section may have a less variable microbiome, which may affect health in later life. ${ }^{12}$ Professor William Cookson (London) discussed the microbiome in asthma and chronic obstructive pulmonary disease (COPD) and showed severe disease is associated with higher frequencies of streptococcal species in the lung microbiome. Professor Stuart Elborn (Belfast) talked about the complex microbiome in cystic fibrosis patients, where it is difficult to distinguish between pathogens and commensal organisms. There also seems to be a correlation between low species richness (ie, number of different bacterial species) and poor outcome in this group of patients.

\section{COPD}

Improving the outcome from exacerbations of COPD was the subject of the first symposium of the BTS Winter Meeting. Dr Jennifer Quint (London) reviewed the risk from exacerbations and described how the complexity and multifactorial nature of these events made prediction of outcome difficult. This was followed by presentations on three interventions that have been the focus of increasing interest and are proposed to improve outcome. Dr Neil Greening (Leicester) described periexacerbation pulmonary rehabilitation, demonstrating good evidence for post-exacerbation rehabilitation but poor uptake, ${ }^{13}$ and new evidence from an impressively large randomised controlled trial of early rehabilitation starting at the time of hospitalisation that had a negative primary outcome with no change in hospitalisation frequency or differences in physical performance, although large natural recovery was seen. ${ }^{14}$ Tele-health was considered next by Dr Hiliary Pinnock (Edinburgh), who showed that the evidence is not as robust as government announcements would suggest. ${ }^{15}$ Finally, more positive outcomes were discussed by Dr James Calvert (Bristol) concerning findings from the BTS COPD admission bundle. Correct oxygen prescription and rapid treatment (two of the five elements of the care bundle) were associated with improved mortality. The correct oxygen management and acidosis management elements of the care bundle were also associated with a lower length of hospital stay. Further abstracts on COPD exacerbations were presented later in the meeting, with Dr Kon (London) demonstrating that a measure of frailty, the $4 \mathrm{~m}$ gait speed, which can be performed near the bed side, predicts mortality following hospitalisation. ${ }^{16}$ Extra-pulmonary effects were also demonstrated with premature cardiovascular ageing in COPD using aortic pulse wave velocity. ${ }^{17}$

Away from specific diseases and covering the symptoms of breathlessness, Professor Miriam Johnson (Hull) discussed the management of refractory breathlessness. All clinicians who manage patients with advanced disease will recognise the inherent difficulties. Treatments included facial airflow, low dose opiates and oxygen therapy, with a systematic review and meta-analysis for the last published the same day in Thorax demonstrating a benefit of oxygen on breathlessness, but with a limited evidence base. ${ }^{18}$ Dr Kyle Pattison (Oxford) demonstrated the importance of the brain and neural mechanisms for breathlessness using fMRI. ${ }^{19}$

The National Secondary Care COPD audit was conducted earlier in 2014 and its results were presented by Dr Robert Stone (Taunton). The largest ever COPD patient dataset was collected and showed improvements in palliative care, non-invasive ventilation and early discharge services, but a number of issues were identified including access to spirometry, smoking cessation and pulmonary rehabilitation.

\section{RESPIRATORY INFECTIONS}

Bronchiectasis was prominent at this year's winter meeting. The reason for this was perhaps best demonstrated by Navaratnam et $a l^{20}$ who used hospital episode statistics to demonstrate a near doubling in the number of hospital admissions for bronchiectasis in England from 2004 to 2011. Bronchiectasis is becoming more common and more costly (figure 1 ).

This was the setting for the symposium 'New developments in bronchiectasis' on Friday morning. The session began with Dr Tony De Soyza (Newcastle) discussing important new developments in bronchiectasis research. The award of a large Medical Research Council (MRC) grant to establish a UK bronchiectasis network and biobank was celebrated as the first step towards facilitating a better understanding of this disease. Alongside international initiatives including the European Respiratory Society-sponsored European Bronchiectasis Registry (EMBARC), these networks should facilitate better clinical trials and Dr De Soyza emphasised that the UK is already a leading destination for commercial and academic clinical studies in bronchiectasis. Emerging antibiotic and anti-inflammatory therapies for bronchiectasis were discussed, reflecting on the fact that this once neglected disease now has a pipeline of potential new therapies. 
Figure 1 Increasing rates of hospitalisation for bronchiectasis.

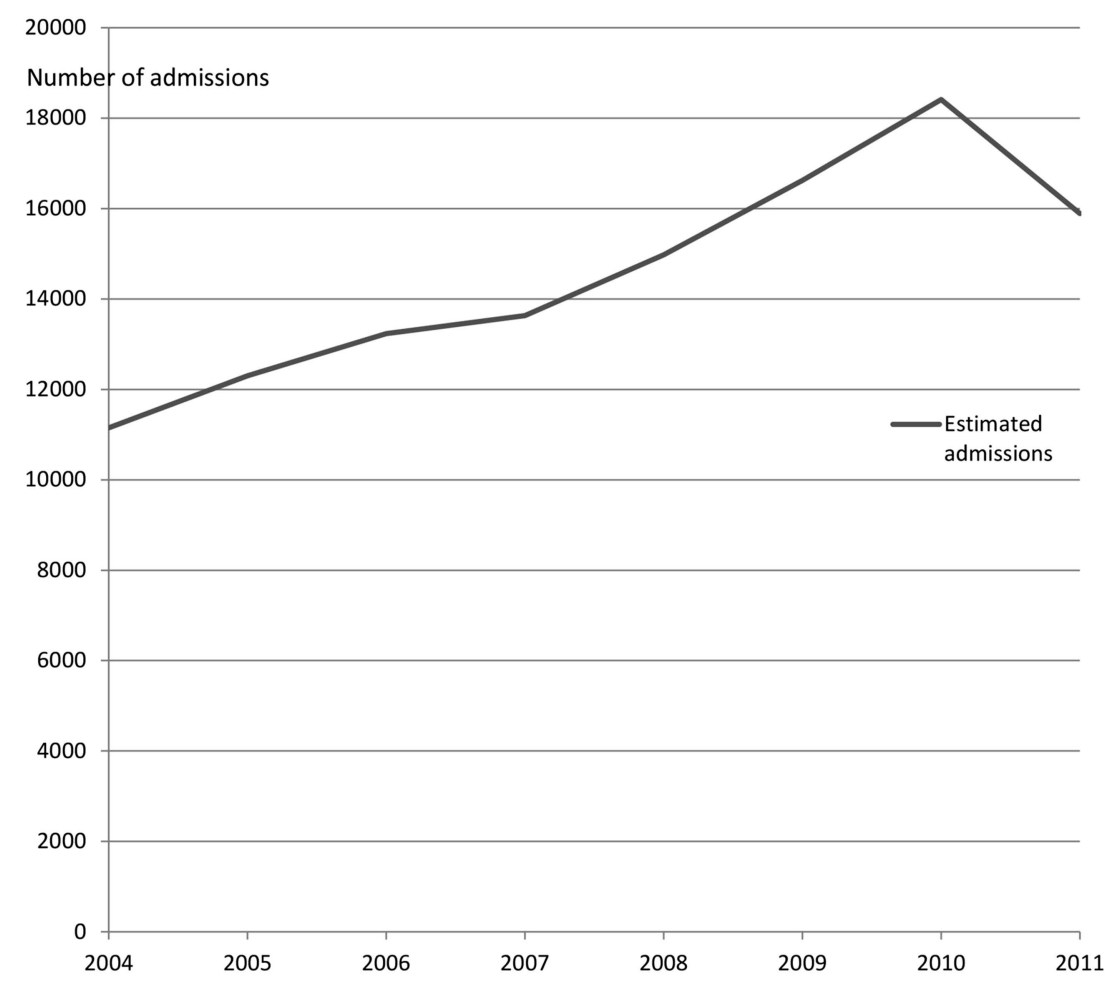

Dr Charles Haworth (Cambridge) outlined the challenges of treating chronic Pseudomonas aeruginosa infection. This pathogen is associated with high mortality, rapid lung function decline and decreased quality of life, but there is no consensus on how best to deal with it. ${ }^{21}$ Dr Haworth described an international randomised controlled trial of inhaled colistin, which he led, that narrowly failed to meet its primary end-point of improved time to first exacerbation, but which had a highly significant effect on this end-point and on quality of life in patients who had adhered to therapy, ${ }^{22}$ a timely reminder that patients have to take their treatment in order to derive benefit. Dr Michael Loebinger (London) gave an excellent talk on the growing worldwide problem of non-tuberculous mycobacterial (NTM) infection. Although the incidence is increasing at rate of $2.9-8.2 \%$ per year, it is also frequently underdiagnosed and underestimated. ${ }^{23}$ Data point to a unique immunological phenotype and even morphotype, and Dr Loebinger presented data linking NTM infection with defects in interferon gamma in affected patients.

The final presentation on the role of macrolides provided an excellent platform for discussion. Several trials now support the use of macrolides in bronchiectasis, but there is no agreement on the best choice of drug, duration or dose. Dr Hill (Edinburgh) presented the evidence to date. ${ }^{24}$

Statins were once promoted as a panacea for treating a range of inflammatory airways diseases and have shown remarkable anti-inflammatory effects in animal and experimental models of asthma, COPD and infections. However, clinical trials have been very disappointing; most recently, an RCT of 885 COPD patients randomised to simvastatin or placebo found no impact on exacerbations. ${ }^{25}$ Statins made a minor comeback at the winter meeting with a report by Mandal et $\mathrm{al}^{26}$ that atorvastatin significantly improved cough in a randomised controlled trial (30 patients receiving atorvastatin vs 30 patients receiving placebo), possibly by promoting neutrophil apoptosis.

Saleh et al used a recently described severity assessment tool for bronchiectasis to study the extent of bronchiectasis in patients with primary immunodeficiency. ${ }^{27} 28$ They found that, consistent with other reports, patients managed in specialist immunodeficiency services have a good prognosis with preserved lung function and a low frequency of colonisation with $P$. aeruginosa.

The winter meeting coincided with the publication of the National Institute for Health and Care Excellence (NICE) guidelines for pneumonia and so this was always bound to be a hot topic at the meeting. ${ }^{29}$ One of the major findings of the guidelines was an almost complete lack of UK data on the management of hospital-acquired pneumonia (HAP), and so it was refreshing to see a study by Burton et al describing the incidence and risk factors for HAP in a large cohort of 1302 patients. Perhaps not surprisingly, aspiration was a major risk factor and mortality was high. ${ }^{30}$ HAP is a key area of unmet need in respiratory medicine.

Hospitalisations for pneumonia are increasing, a message reinforced by Millett et $a l^{31}$ who could find no clear explanation for the rise and suggested the possibility that changes in the health service may be driving an increased tendency to refer patients to hospital. The likelihood of hospitalisation for pneumonia increased by almost 30\% over 10 years, suggesting a major shift in practice that could have important implications for healthcare costs.

\section{TUBERCULOSIS}

Tuberculosis (TB) remains a major challenge, but our own problems pale into insignificance compared to those of Eastern Europe, which now has the unwanted status of a world leader in multidrug resistant TB (MDR). For example, a recent study from Belarus showed that $35 \%$ of new TB diagnoses and $75 \%$ of new TB diagnoses in those previously treated for TB were MDR or extensively drug-resistant (XDR) TB cases. ${ }^{32}$ Professor Christoph Lange (Borstel, Germany) outlined this growing problem, emphasising the need for solutions at a European and global level. 
Professor Stephen Gillespie (St Andrews) next presented a groundbreaking clinical trial-the ReMoxTB trial. This was an extraordinary international effort, randomising 1931 patients in South Africa, India, Tanzania, Kenya, Thailand, Malaysia, Zambia, China and Mexico. ${ }^{33}$ The study aimed to reduce the duration of antibiotic therapy for TB from 6 to 4 months using a moxifloxacin-based regime. Despite moxifloxacin resulting in a more rapid decline in bacterial load, the shorter regimes containing moxifloxacin showed a higher relapse rate than the standard 6-month regime, which will consequently remain the standard of care internationally. Finally, Professor Beate Kampmann (London) reviewed the specific clinical challenges of treating TB, and latent TB infection, in children. London has a high proportion of the TB cases in the UK. Ferenando et $a l^{34}$ presented an abstract describing a very high frequency of latent TB infection in hard-to-reach groups (homeless people, substance misusers and prisoners) in London, along with high rates of blood-borne virus co-infection. A higher than expected prevalence of blood-borne viruses in TB cases was confirmed in a separate abstract by Potter et al, ${ }^{35}$ who advocated changing national guidelines to recommend routine screening for hepatitis $\mathrm{B}$ and $\mathrm{C}$ in patients with active tuberculosis. Vitamin D deficiency was an important discussion topic in the 2013 winter meeting review, but in a study by Sloan et $\mathrm{al}^{36}$ was found not to have any effect on treatment response during $\mathrm{TB}$ infection in adults in Malawi.

\section{INTERSTITIAL LUNG DISEASE}

Idiopathic pulmonary fibrosis (IPF) has recently received much attention from the respiratory community as two important clinical trials have been published that demonstrate a positive effect on clinical outcomes of two drugs, pirfenidone ${ }^{37}$ and nintedanib. ${ }^{38}$ At this year's BTS Winter Meeting, the IPF sessions were very well attended with full auditoriums. Dr Martin Kolb (Ontario, Canada) kicked off with an interesting lecture that reminded us that IPF has worse outcomes than most cancers although the pathobiology has many similarities, and that one day this disease may need to be targeted in the same way that oncologists have managed cancer. Dr Gisli Jenkins (Nottingham) discussed the role of imaging in the diagnosis of IPF and using features of the disease on CT chest scans to assist with outcome prediction, while biomarkers such as MMP3 and $\mathrm{CXCL13}^{39}$ may in the future allow for stratification of IPF patients and targeted therapies, opening an era of personalised medicine. Dr Andrew Wilson (Norwich) discussed the pulmonary microbiome in IPF and suggested that antibiotics may have a role in improving patient outcomes. ${ }^{40}$ Dr Nik Hirani (Edinburgh) ended the session by demonstrating how patients treated in his local practice would not fulfil the criteria for enrolment in recently conducted IPF clinical drug trials, making it hard to generalise the results of these trials to the majority of IPF patients seen in clinical practice. The 'Basic mechanisms in IPF' session highlighted novel basic science research in this field, including identification of the kinase selectivity profiles of compounds trialled for the treatment of IPF. ${ }^{41}$ In this session Miss Al-Juffali (London), winner of the BTS medical student prize, presented her elegant research on the use of nanodiamonds to deliver vascular endothelial growth factor (VEGF) to promote fetal lung development in a rat model of congenital diaphragmatic hernia. ${ }^{42}$

\section{ACUTE LUNG INJURY}

Acute lung injury (ALI) is a major cause of morbidity and mortality, and this year the BTS heard from experts in this field working on understanding the mechanisms of ALI for drug development. Professor Rachel Chambers (London) gave an insightful overview of the known pathomechanisms leading to the development of ALI, especially focusing on novel work from her group on the interplay between coagulation and inflammation, ${ }^{43}$ in particular the role of neutrophilic inflammation. ${ }^{44}$ Professor Danny McAuley (Belfast) discussed his experience of investigator-led studies for the translation of findings from experimental models to human clinical trials in the development of new therapeutics for patients with ALI, which is a difficult task that is made even harder by the heterogeneity associated with the disease. ${ }^{45}$ Due to the paucity of effective therapeutics for the treatment of ALI, the talk presented by Dr Daniel Talmor (Boston, USA) discussed identifying patients at risk and focusing therapeutic strategies towards preventing the development of acute respiratory distress syndrome (ARDS) in this group of patients. Finally, Dr Andrew Bayliffe (London) described the important contribution of the pharmaceutical industry.

The session on mechanistic insights into ALI allowed young investigators to demonstrate their research in this field. The session included a description of a novel human model to study alveolar injury and repair using precision-cut lung slices, ${ }^{46}$ investigations highlighting important roles for TNFR1 in neutrophilendothelial interactions, ${ }^{47}$ and proteinase-activated receptor-1 signalling in pneumococcal pneumonia-induced lung injury, ${ }^{48}$ as well as the role of lipoxin A4 in improving efferocytosis in ARDS. ${ }^{49}$

\section{PLEURAL DISEASE}

The symposium on pleural disease on the opening day of the BTS Winter Meeting was very well attended with emerging enthusiasm in pleural disease apparent among our colleagues. This session included three entertaining and humorous pro-con debates on the use of the BTS guidelines for the management of primary spontaneous pneumothorax by Dr John Harvey (Bristol) and Dr Andrew MacDuff (Wolverhampton). We were reminded that even though there isn't a body cavity that can't be reached with a needle, ${ }^{50}$ we should always treat the patient and not the air on the chest radiograph. Dr Mark Slade (Cambridge) and Dr Mohammed Munavvar (Preston) debated the use of indwelling pleural catheters in the management of malignant pleural effusions; these catheters may change our management of these pleural effusions, facilitating outpatient care and improving integrated care. The final pro-con debate was on the management of empyema not responding to initial medical therapy. Mr John Edwards (Sheffield) advocated early video-assisted thoracic surgery (VATS), demonstrating excellent outcome, while Dr Alex West (London) provided evidence that surgery was rarely required with the use of DNAse and thrombolytics. ${ }^{51}$

\section{\#BTSWINTER}

The BTS Winter Meeting further increased its presence on social media in 2014. A total of 3110 tweets from 431 participants saw discussions reaching beyond the walls of the conference centre and debate by delegates within sessions. Figure 2 shows the most used words in tweets on the meeting, an insight into the particular areas of debate and interest.

\section{CONCLUSIONS}

The 2014 BTS Winter Meeting provided delegates with both fantastic reviews of cutting-edge respiratory science and research and presentations of original data. For those busy digesting all 
Figure 2 Words associated with the \#BTSWinter hashtag and used most frequently on Twitter during the BTS Winter Meeting.

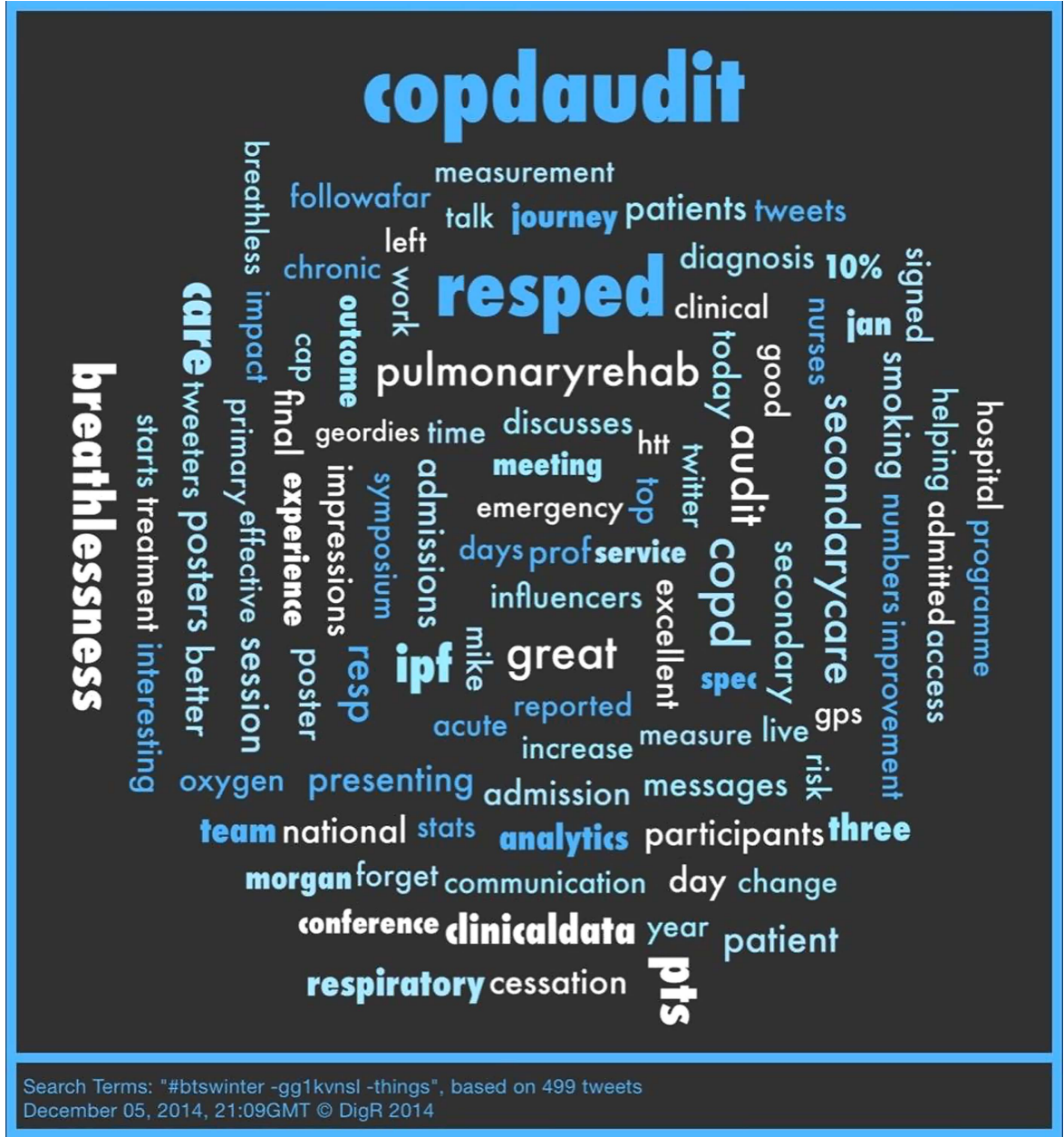

this information and trying to follow their obligatory New Year resolutions of more exercise and better diet, the final abstract in this review is reserved for Curtis et al, ${ }^{52}$ who described an interventional cross-over study of supplemental beetroot juice with cycle ergometry, showing a significant reduction in oxygen consumption and diastolic blood pressure in patients with COPD!

Acknowledgements The authors would like to acknowledge all those at the British Thoracic Society for the organisation of the Winter Meeting and Dr Andrew Williams for his contribution to the section in this review on the British Paediatric Respiratory Society session.

Contributors NJG, RJJ, JDC and SMJ were responsible for review, research and writing of the manuscript. SMJ was responsible for the concept of the manuscript.

Competing interests None.

Provenance and peer review Commissioned; internally peer reviewed.

\section{REFERENCES}

1 Wilson R, Cohen JM, Jose RJ, et al. Protection against Streptococcus pneumoniae lung infection after nasopharyngeal colonization requires both humoral and cellular immune responses. Mucosal Immunol Published Online First: 29 Oct 2014. doi:10.1038/mi.2014.95

2 Wright AK, Ferreira DM, Gritzfeld JF, et al. Human nasal challenge with Streptococcus pneumoniae is immunising in the absence of carriage. PLoS Pathogens 2012;8:e1002622.

3 Angulo I, Vadas 0, Garcon F, et al. Phosphoinositide 3-kinase delta gene mutation predisposes to respiratory infection and airway damage. Science 2013:342:866-71.

4 Cottin V, Richeldi L. Neglected evidence in idiopathic pulmonary fibrosis and the importance of early diagnosis and treatment. Eur Respir Rev 2014:23:106-10.

5 Wenzel SE. Asthma phenotypes: the evolution from clinical to molecular approaches. Nat Med 2012;18:716-25.
6 Moore WC, Meyers DA, Wenzel SE, et al. Identification of asthma phenotypes using cluster analysis in the Severe Asthma Research Program. Am J Respir Crit Care Med 2010;181:315-23.

7 Haldar P, Pavord ID, Shaw DE, et al. Cluster analysis and clinical asthma phenotypes. Am J Respir Crit Care Med 2008;178:218-24.

8 Bos Kl, Harkins KM, Herbig A, et al. Pre-Columbian mycobacterial genomes reveal seals as a source of New World human tuberculosis. Nature 2014;514:494-7.

9 Scotton CJ, Hayes B, Alexander R, et al. Ex vivo micro-computed tomography analysis of bleomycin-induced lung fibrosis for preclinical drug evaluation. Eur Respir J 2013:42:1633-45.

10 Robertson AL, Holmes GR, Bojarczuk AN, et al. A zebrafish compound screen reveals modulation of neutrophil reverse migration as an anti-inflammatory mechanism. Sci Trans/ Med 2014;6:225ra29.

11 Bisgaard $\mathrm{H}$, Hermansen MN, Bønnelykke $\mathrm{K}$, et al. Association of bacteria and viruses with wheezy episodes in young children: prospective birth cohort study. BMJ 2010:341:c4978

12 Sevelsted A, Stokholm J, Bonnelykke K, et al. Cesarean section and chronic immune disorders. Pediatrics 2015;135:e92-8.

13 Jones SE, Green SA, Clark AL, et al. Pulmonary rehabilitation following hospitalisation for acute exacerbation of COPD: referrals, uptake and adherence. Thorax 2014:69:181-2.

14 Greening NJ, Williams JE, Hussain SF, et al. An early rehabilitation intervention to enhance recovery during hospital admission for an exacerbation of chronic respiratory disease: randomised controlled trial. BMJ 2014;349:g4315.

15 Pinnock $\mathrm{H}$, Hanley J, McCloughan L, et al. Effectiveness of telemonitoring integrated into existing clinical services on hospital admission for exacerbation of chronic obstructive pulmonary disease: researcher blind, multicentre, randomised controlled trial. BMJ 2013;347:f6070.

16 Kon S, Jones S, Schofield S, et al. S81 Gait speed is a predictor of mortality following hospitalisation for acute exacerbations of COPD. Thorax 2014;69(Suppl 2): A45.

17 Gale N, Albarrati A, Munnery M, et al. M143 Progression of central arterial stiffness in COPD after 2 years of observation. Thorax 2014;69(Suppl 2):A214-A15.

18 Uronis HE, Ekström MP, Currow DC, et al. Oxygen for relief of dyspnoea in people with chronic obstructive pulmonary disease who would not qualify for home 
oxygen: a systematic review and meta-analysis. Thorax Published Online First: 3 Dec 2014. doi:10.1136/thoraxjnl-2014-205720

19 Pattinson KT, Johnson MJ. Neuroimaging of central breathlessness mechanisms. Curr Opin Support Palliat Care 2014;8:225-33.

20 Navaratnam V, Millett E, Hurst J, et al. P81 The increasing secondary care burden of bronchiectasis in England. Thorax 2014;69(Suppl 2):A111-A12.

21 Loebinger MR, Wells AU, Hansell DM, et al. Mortality in bronchiectasis: a long-term study assessing the factors influencing survival. Eur Respir J 2009;34:843-9.

22 Haworth CS, Foweraker JE, Wilkinson P, et al. Inhaled colistin in patients with bronchiectasis and chronic Pseudomonas aeruginosa infection. Am J Respir Crit Care Med 2014;189:975-82.

23 Adjemian J, Olivier KN, Seitz AE, et al. Prevalence of nontuberculous mycobacterial lung disease in U.S. Medicare beneficiaries. Am J Respir Crit Care Med 2012;185:881-6.

24 Haworth CS, Bilton D, Elborn JS. Long-term macrolide maintenance therapy in non-CF bronchiectasis: evidence and questions. Respir Med 2014;108:1397-408.

25 Criner GJ, Connett JE, Aaron SD, et al. Simvastatin for the prevention of exacerbations in moderate-to-severe COPD. N Engl J Med 2014;370:2201-10.

26 Mandal P, Chalmers JD, Graham C, et al. Atorvastatin as a stable treatment in bronchiectasis: a randomised controlled trial. Lancet Respir Med 2014;2:455-63.

27 Chalmers JD, Goeminne P, Aliberti S, et al. The bronchiectasis severity index. An international derivation and validation study. Am J Respir and Crit Care Med 2014;189:576-85

28 Saleh A, Hurst J, Davison J, et al. P79 Bronchiectasis severity in primary immunodeficiency: a two centre study. Thorax 2014;69(Suppl 2):A110-A11.

29 Eccles S, Pincus C, Higgins B, et al. Diagnosis and management of community and hospital acquired pneumonia in adults: summary of NICE guidance. BMJ 2014;349. g6722.

30 Burton L, Price R, Barr K, et al. S13 Incidence and risk factors for the development of hospital acquired pneumonia in older hospitalised patients. Thorax 2014;69 (Suppl 2):A9-A10.

31 Millett E, De Stavola B, Quint J, et al. S14 Time trends and risk factors for hospitalisation after community-acquired pneumonia in older adults in England. Thorax 2014;69(Suppl 2):A10.

32 Skrahina A, Hurevich $H$, Zalutskaya $A$, et al. Alarming levels of drug-resistant tuberculosis in Belarus: results of a survey in Minsk. Eur Respir J 2012;39:1425-31.

33 Gillespie SH, Crook AM, McHugh TD, et al. Four-month moxifloxacin-based regimens for drug-sensitive tuberculosis. N Engl J Med 2014;371:1577-87.

34 Ferenando G, Hemming S, Yates S, et al. S61 High levels of latent TB infection, blood borne viruses, poor treatment outcomes and unmet need among hard to reach groups in London: the TB reach study. Thorax 2014;69(Suppl 2):A34.

35 Potter J, Hyams C, Shaukat M, et al. P189 Should screening for chronic viral hepatitis in patients with tuberculosis be introduced to NICE guidelines? Thorax 2014;69(Suppl 2):A159.
36 Sloan D, Guwende C, Banda G, et al. S75 Risk factors and therapeutic implications of vitamin D deficiency in Malawian adults with pulmonary tuberculosis. Thorax 2014;69(Suppl 2):A42.

37 King TE Jr, Bradford WZ, Castro-Bernardini S, et al. A phase 3 trial of pirfenidone in patients with idiopathic pulmonary fibrosis. N Engl J Med 2014;370: 2083-92.

38 Richeldi L, du Bois RM, Raghu G, et al. Efficacy and safety of nintedanib in idiopathic pulmonary fibrosis. N Engl J Med 2014;370:2071-82.

39 DePianto DJ, Chandriani S, Abbas AR, et al. Heterogeneous gene expression signatures correspond to distinct lung pathologies and biomarkers of disease severity in idiopathic pulmonary fibrosis. Thorax 2015;70:48-56.

40 Shulgina L, Cahn AP, Chilvers ER, et al. Treating idiopathic pulmonary fibrosis with the addition of co-trimoxazole: a randomised controlled trial. Thorax 2013;68:155-62.

41 Rajagopalan R, Nicholas J, Misialek S, et al. S134 Kinase selectivity profiles of Nintedanib and Imatinib. Thorax 2014;69(Suppl 2):A72.

42 Al-Juffali N, Loukogeorgakis S, Jimenez J, et al. S138 Nanodiamond delivery of vascular endothelial growth factor promotes fetal lung development in a rat model of congenital diaphragmatic hernia. Thorax 2014;69(Suppl 2): A73-4.

43 Jose RJ, Williams AE, Chambers RC. Proteinase-activated receptors in fibroproliferative lung disease. Thorax 2014;69:190-2.

44 Williams AE, Chambers RC. The mercurial nature of neutrophils: still an enigma in ARDS? Am J Physiol Lung Cell Mol Physiol 2014;306:L217-30.

45 Curley GF, McAuley DF. Clinical trial design in prevention and treatment of acute respiratory distress syndrome. Clin Chest Med 2014;35:713-27.

46 Alçada J, Ng-Blichfeldt J, Proudfoot A, et al. 598 A novel human model to study alveolar injury and repair. Thorax 2014;69(Suppl 2):A53.

47 Proudfoot A, Juss J, Appleby S, et al. S99 Effects of differential TNF receptor signalling in modulating neutrophil-endothelial interactions in the pulmonary microvasculature. Thorax 2014;69(Suppl 2):A53.

48 José R, Williams A, Sulikowski M, et al. S100 Proteinase-activated receptor 1 signalling contributes to neutrophilic inflammation and alveolar barrier disruption in Streptococcus pneumoniae pneumonia. Thorax 2014;69(Suppl 2):A53-4.

49 Wang Q, Parekh D, D'Souza V, et al. S102 Lipoxin A4 improves efferocytosis via inhibition of the HMGB1 in human alveolar macrophages. Thorax 2014;69(Suppl 2): A54-5.

50 Shem S. The House of God. Penguin Group US, 2010.

51 Rahman NM, Maskell NA, West A, et al. Intrapleural use of tissue plasminogen activator and DNase in pleural infection. N Engl J Med 2011;365:518-26.

52 Curtis K, Tanner R, O'Brien K, et al. M144 acute dietary nitrate supplementation reduces the oxygen cost of submaximal exercise in COPD. Thorax 2014;69(Suppl 2): A215. 